\title{
Announcement
}

\section{9th Annual Meeting of the Society for the Study of Reproduction} Ithaca, N.Y., USA, July 15-17, 1986

The 19th Annual Meeting of the Society for the Study of Reproduction will be held at Cornell University in Ithaca, N.Y., USA, from July 15 through 17, 1986.

The program will include a Symposium on Neuroendocrinol-ogy, two state-of-the-art lectures and an awards ceremony as well as sessions devoted to research papers. To obtain additional information about the Symposium or submission of contributed papers, please contact:

\section{Executive Secretary,}

The Society for the Study of Reproduction,

309 West Clark Street,

Champaign, IL 61820 (USA) 